\title{
Dessecação em pré-semeadura e modos de aplicação de herbicida em pós-emergência combinado ou não a regulador de crescimento em híbridos de milho
}

Dessication in pre-seeding and modes since aplication of herbicide in combinated post-emergence or not to growth regulate in corn hibrids

Camila Ferreira, cferreira87@hotmail.com Jeferson Zagonel, jefersonzagonel@uol.com.br Marina Senger, marina_senger@hotmail.com Allan Christian de Souza, allan.uepg@gmail.com
Resumo: O trabalho objetivou avaliar os efeitos da dessecação em pré-semeadura, do modo de aplicação de herbicida em pós-emergência e da aplicação de trinexapac-ethyl na cultura do milho, em dois anos consecutivos. O delineamento experimental foi em blocos ao acaso, com esquema fatorial $2 \times 2$ × (com e sem dessecação em pré-semeadura x aplicação única e sequencial de herbicida em pós-emergência x com e sem aplicação de regulador de crescimento), com quatro repetições. Os tratamentos constaram da dessecação ou não em pré-semeadura com $400 \mathrm{~g}$ ha-1 de paraquate, do modo de aplicação, única ou sequencial, do herbicida em pós-emergência mesotriona + atrazina para o híbrido Status TL e glifosato para o Maximus TLTG, além da aplicação ou não de trinexapac-ethyl. Avaliaram-se características morfológicas, componentes de rendimento e produtividade. Na safra 2010/11 a dessecação causou aumento da altura de plantas e maior produtividade para ambos os híbridos. A aplicação sequencial de herbicidas ocasionou maior número de fileiras por espiga para o Status TL e a aplicação do trinexapac-ethyl não promoveu alterações nas características avaliadas nessa safra. Na safra 2011/12, a dessecação em pré-semeadura promoveu maior produtividade no Maximus TLTG. Para o Status TL a dessecação em pré-semeadura resultou em maior número de espigas por planta. O modo de aplicação de herbicidas não alterou de maneira substancial as características avaliadas nos dois híbridos. A aplicação do trinexapac-ethyl resultou na diminuição da área foliar e do índice de área foliar do Maximus TLTG.

Palavras-chave: Zea mays L.; trinexapac-ethyl; glifosato; mesotriona.

Abstract: The study intended to evaluate the effects of desiccation in pre-seeding, of the herbicide application's mode in post-emergence and the application of trinexapac-ethyl of corn, in two consecutive years. The experimental design was made in randomized block with factorial scheme $2 \times 2 \times 2$ (with and without desiccation in pre-seeding $\times$ single and sequential application of herbicide in postemergence $x$ with and without application of growth regulator), with four repetitions. The treatments consisted of the desiccation or not in pre-seeding with $400 \mathrm{~g}$ ha-1 paraquat, the mode of application, single or sequential, of herbicides in post-emergence mesotrione + atrazine for hybrid Status $T L$ and glyphosate for Maximus TLTG, besides the application or not of trinexapac-ethyl. Morphological characteristics, yield components and grain yield were evaluated. In 2010/11 crop the desiccation promoted an increase in plant height and greater yield for both hybrids. The sequential application of herbicides caused greater number of rows per ear for Status $T L$ and the application of trinexapac-ethyl did not cause changes in the characteristics evaluated in this crop. In 2011/12 the desiccation in pre-seeding promoted a grain yield increase in Maximus TLTG. To Status TL the desiccation on the day of seeding resulted in a greater number of ears per plant. The application's mode of post-emergence herbicides did not affect substantially the characteristics evaluated in the two hybrids. The application of trinexapac-ethyl resulted in decrease of leaf area and leaf area index of Maximus TLTG.

Keywords: Zea mays L.; trinexapac-ethyl; glyphosate; mesotrione. 
O manejo das plantas daninhas compreende uma série de aplicações, desde o manejo em pré-semeadura até o controle em pós-emergência. A introdução de culturas resistentes a herbicidas no mercado tem afetado o modo de controle das plantas daninhas, especialmente no caso da soja e do milho (PHIPPS; PARK, 2002).

Quando se comparam culturas como o milho convencional e o transgênico, constata-se que o crescimento é similar, devendo, portanto, receber o mesmo manejo cultural, seja no que tange à época de semeadura, ao manejo de pragas e de doenças e à densidade de plantas, entre outros, sendo imprescindível o conhecimento da fenologia da cultura. Isso não é diferente em relação à época de aplicação dos herbicidas em pós-emergência, visto que os períodos de matocompetição são os mesmos para o milho transgênico ou não, devendo o controle ser iniciado num período de 5 a 19 dias a partir da semeadura conforme as condições do local (KOZLOWSKI, 2002; NORSWORTHY; OLIVEIRA, 2004).

Para o manejo das plantas daninhas em pré-semeadura alguns aspectos devem ser considerados. Primeiro, o estádio das plantas daninhas e, segundo, a época em que a dessecação será realizada em relação à semeadura. A época de aplicação dos herbicidas em pré-semeadura não é bem definida, pois varia com os fatores de campo, como espécies presentes, população, cultura anterior, entre outros. No entanto, o procedimento pode ser realizado em aplicação única de 5 a 10 dias antes da semeadura ou sequencialmente com a primeira antecipada e a segunda próxima da semeadura, quando em cada uma delas pode se optar pelo herbicida mais adequado às plantas daninhas predominantes (ZAGONEL; MAROCHI, 2004). Para o controle antecipado em geral utiliza-se o glifosato, e na aplicação próxima da semeadura utiliza-se o paraquate (SOUZA et al., 2000).

$\mathrm{O}$ controle em pós-emergência do milho RR é realizado com glifosato, combinado ou não a outros herbicidas, aqueles recomendados para o milho convencional. Essa técnica permite a rotação de herbicidas, evitando-se a resistência. Em milho convencional, em geral são utilizados herbicidas do grupo das tricetonas, entre os quais o mesotriona, um dos mais utilizados, que controla espécies de folhas estreitas, mas também é eficaz sobre algumas espécies de folhas largas. No entanto, a eficiência máxima desse herbicida é obtida quando em mistura com a atrazina (ARMEL et al., 2003).

Almejando sempre alcançar altas produtividades, além do controle de plantas daninhas há também a adoção de altas populações de plantas e elevadas doses de nitrogênio. Porém, com o uso dessas técnicas a cultura fica mais suscetível à ocorrência de acamamento, devido ao aumento da estatura de plantas. Para possibilitar o uso de maiores densidades de semeadura e doses de nitrogênio sem que ocorra o acamamento, pode-se utilizar cultivares de porte baixo ou reguladores de crescimento, os quais são utilizados na cultura do trigo com excelentes resultados (ZAGONEL; FERNANDES, 2007).

O trinexapac-ethyl é um regulador de crescimento que atua reduzindo a elongação celular no estádio vegetativo das plantas, interferindo no final da rota metabólica da biossíntese do ácido giberélico (RAJALA, 2003) pela inibição da enzima $3 \beta$-hidroxilase, reduzindo drasticamente 0 nível do ácido giberélico ativo (GA1) e assim aumentando acentuadamente seu precursor biossintético imediato GA20 (DAVIES, 1987). A queda no nível do ácido giberélico ativo é a provável causa da diminuição do crescimento das plantas (RADEMACHER, 2000; WEILER; ADAMS, 1991).

Nesse sentido, realizaram-se dois experimentos, em dois anos consecutivos, com o objetivo de avaliar os efeitos da dessecação em pré-semeadura, do modo de aplicação de herbicidas de pós-emergência e da aplicação do regulador de crescimento trinexapac-ethyl na cultura do milho.

\section{Material e mÉtOdos}

Os experimentos foram conduzidos nas safras 2010/11 e 2011/12, na Fazenda Escola da Universidade Estadual de Ponta Grossa - UEPG, situada no município de Ponta Grossa, Paraná, geograficamente localizado na latitude $25^{\circ} 5^{\prime} 49^{\prime \prime}$ e longitude $50^{\circ} 3^{\prime} 11^{\prime \prime}$, a uma altitude de $1.025 \mathrm{~m}$. O solo no local dos experimentos foi caracterizado como Cambissolo Háplico distrófico típico de textura argilosa. A análise química do solo, em amostragem de 0 a $10 \mathrm{~cm}$, revelou os resultados: $\mathrm{pH}\left(\mathrm{CaCl}_{2}\right)=5,0 ; \mathrm{Ca}^{++}=4,0 \mathrm{cmol}_{\mathrm{C}} \mathrm{dm}^{-3} ; \mathrm{Ca}+$ $\mathrm{Mg}=6,5 \mathrm{cmol}_{\mathrm{C}} \mathrm{dm}^{-3} ; \mathrm{K}=0,52 \mathrm{cmol}_{\mathrm{C}} \mathrm{dm}^{-3} ; \mathrm{P}=11,1 \mathrm{mg}$ $\mathrm{dm}^{-3} ; \mathrm{C}=38 \mathrm{~g} \mathrm{dm}^{-3} ; \mathrm{H}+\mathrm{Al}=6,21 \mathrm{cmol}_{\mathrm{C}} \mathrm{dm}^{-3}, \mathrm{Al}^{+++}$ $=0,0 ; \mathrm{CTC}=13,23 ; \mathrm{V} \%=53$, e a análise granulométrica, em $\mathrm{g} \mathrm{kg}^{-1}$ : argila - 460; silte - 179; areia - 361. O clima da região é correspondente $\mathrm{a} \mathrm{Cfb}$, segundo a classificação de Köppen, possui clima temperado propriamente dito, o qual se caracteriza por possuir verões frescos, com ausência de estação seca definida.

O delineamento experimental utilizado nas duas safras foi de blocos ao acaso, em esquema fatorial $2 \times 2 \times 2$ (com ou sem dessecação da área no dia da semeadura $x$ aplicação única ou sequencial de herbicida em pós-emergência $x$ com ou sem aplicação de trinexapac-ethyl junto ao herbicida em pós-emergência), com quatro repetições. Nos dois anos as parcelas continham área total de $24,0 \mathrm{~m}^{2}(6,0 \mathrm{x}$ $4,0 \mathrm{~m})$ e área útil de $12,0 \mathrm{~m}^{2}(5,0 \times 2,4)$, sendo as fileiras espaçadas em 0,8 metros. Os tratamentos constaram da dessecação ou não da área de cada experimento com 400 
$\mathrm{g} \mathrm{ha}^{-1}$ de paraquate no dia da semeadura; da aplicação única, no estádio vegetativo V4, ou sequencial, nos estádios V2N3 e V5N6 do milho, segundo escala fenológica de Hanway (1966); da aplicação ou não do regulador de crescimento trinexapac-ethyl na dose de $250 \mathrm{~g} \mathrm{ha}^{-1}$ combinado à aplicação de herbicida em pós-emergência. Nas duas safras os tratamentos foram aplicados nos híbridos Status TL e Maximus TLTG, os quais foram considerados experimentos separados.

O sistema de plantio direto foi o adotado nos dois anos de cultivo, sendo a cultura antecessora o trigo. Em ambos os anos as áreas foram dessecadas vinte dias antes da semeadura, com a aplicação de $1240 \mathrm{~g} \mathrm{ha}^{-1}$ de glifosato. Nas duas safras a adubação foi realizada aplicando-se $300 \mathrm{~kg}$ da fórmula química 10-20-20 (30 kg ha-1 de ureia, $60 \mathrm{~kg}$ $\mathrm{ha}^{-1}$ de superfosfato simples e $60 \mathrm{~kg} \mathrm{ha}^{-1}$ de nitrato de potássio). Na adubação de cobertura aplicou-se 112,5 kg $\mathrm{ha}^{-1}$ de ureia, na fase V3 da cultura do milho.

No híbrido Status TL a aplicação única de herbicida foi realizada com $1200 \mathrm{~g} \mathrm{ha}^{-1}$ de atrazina $+120 \mathrm{~g} \mathrm{ha}^{-1} \mathrm{de}$ mesotriona. No milho resistente ao glifosato, Maximus TLTG, a aplicação única foi realizada com glifosato na dose de $1240 \mathrm{~g} \mathrm{ha}^{-1}$. Na aplicação sequencial utilizou-se, em cada aplicação, $800 \mathrm{~g} \mathrm{ha}^{-1}$ de atrazina e $60 \mathrm{~g} \mathrm{ha}^{-1}$ de mesotrione no milho convencional (Status TL) e $744 \mathrm{~g} \mathrm{ha}^{-1}$ de glifosato no milho RR (Maximus TLTG). A dose de trinexapac-ethyl foi de $250 \mathrm{~g} \mathrm{ha}^{-1}$, aplicada em combinação ao tratamento de aplicação única de herbicidas e de $125 \mathrm{~g} \mathrm{ha}^{-1}$ em cada aplicação sequencial.

O trinexapac-ethyl e os herbicidas foram aplicados utilizando-se um pulverizador costal, à pressão constante de $206,85 \mathrm{kPa}$, pressurizado por $\mathrm{CO}_{2}$ comprimido, com bicos munidos de pontas de jato plano "leque" XR 110-015. Aplicou-se o equivalente a $150 \mathrm{~L} \mathrm{ha}^{-1}$ de calda.

No florescimento do milho foram determinadas altura de plantas e de inserção da primeira espiga inferior; comprimento da folha acima e da folha oposta à espiga superior, considerando-se da inserção da folha até a sua ponta; largura da folha acima e da folha oposta à espiga superior, medida na parte mediana de cada folha; a área foliar por planta, a qual avaliou todas as folhas de cinco plantas por parcela utilizando-se o determinador de área foliar da marca Li - COR Biosciences LI - 3100 C area meter. Não houve avaliação de acamamento devido a sua não ocorrência. As avaliações dos componentes de rendimento foram realizadas na época da colheita. O número de espigas por planta foi determinado por meio da contagem do número de espigas e de plantas presentes em dois metros de fileira. O número de fileiras por espiga e de grãos por fileira foram determinados a partir das espigas coletadas em dois metros de fileira. A determinação da produtividade foi realizada a partir da colheita de toda a área útil de cada parcela (12,0 m2). A massa de mil grãos e a produtividade foram determinadas com a correção da umidade para 13\%.

Os dados obtidos foram submetidos à análise de variância pelo teste $F$, e as diferenças entre as médias, quando significativas, foram comparadas pelo teste de Tukey $(P<0,05)$.

\section{RESULTAdOS E DISCUSSÃO}

Não ocorreram interações significativas entre os tratamentos para todas as variáveis analisadas.

A altura de plantas e de inserção da espiga na safra 2010/11 foram maiores com a dessecação realizada em pré-semeadura para os dois híbridos. Na safra 2011/12, a dessecação em pré-semeadura não causou efeito sobre a altura de plantas de ambos os híbridos, havendo diferença somente para a altura de inserção de espiga do híbrido Maximus TLTG (Tabela 1). Constantin et al. (2008), avaliando os efeitos de doses do herbicida glifosato aplicadas na dessecação de manejo de Brachiaria decumbens no sistema aplique e plante sobre o desenvolvimento inicial do milho, observaram que o sombreamento promovido pela presença da palha ereta de $B$. decumbens causou estiolamento no milho. Assim, são confirmados os prejuízos que a matocompetição causa no desenvolvimento inicial da cultura, fase do ciclo de suma importância para o estabelecimento da mesma.

O modo de aplicação de herbicidas não alterou significativamente a altura de plantas e de inserção de espiga em ambos os híbridos nas duas safras (Tabela 1). Apesar de não ter ocorrido diferença estatística entre a aplicação única e sequencial do herbicida em pós-emergência, a aplicação sequencial é uma opção de manejo interessante para o controle de plantas daninhas, pois o parcelamento da dose resulta no aumento da seletividade dos herbicidas sobre as culturas, além de reduzir o banco de sementes das invasoras na área de cultivo. Burke et al. (2008), em pesquisa, comparando a aplicação única e a sequencial de herbicidas na cultura do milho, verificaram que a aplicação sequencial foi mais eficiente no controle de plantas daninhas do que a aplicação única, mas também não se refletiu em diferença na altura das plantas de milho, como observado na presente pesquisa. A altura de plantas e de inserção de espiga do milho também não foram afetadas pela aplicação do regulador de crescimento para ambos os híbridos e nos dois anos agrícolas (Tabela 1). Para Zagonel e Fernandes (2007), em trigo, a resposta da altura de plantas em relação a aplicação de trinexapac-ethyl varia de acordo com a cultivar, com o ano de cultivo e com a época e a dose do 
regulador de crescimento. Portanto, as prováveis causas para os resultados observados no presente trabalho podem ser atribuídas à baixa resposta da cultura do milho, à dose insuficiente ou à época precoce de aplicação, visto que não há estudos relatando a eficiência deste regulador de crescimento para a cultura do milho, assim como dose e época de aplicação adequada.

Tabela 1: Altura de plantas (AP) e altura de inserção de espiga (AE) dos híbridos de milho Status TL e Maximus TLTG, em função da dessecação ou não no dia da semeadura, da aplicação única ou sequencial de herbicida em pós-emergência e do uso ou não do regulador de crescimento trinexapac-ethyl, nas safras 2010/11 e 2011/12. Ponta Grossa - PR

\begin{tabular}{|c|c|c|c|c|c|c|c|c|}
\hline & \multicolumn{2}{|c|}{ Status TL } & \multicolumn{2}{|c|}{ Maximus TL TG } & \multicolumn{2}{|c|}{ Status TL } & \multicolumn{2}{|c|}{ Maximus TL TG } \\
\hline & \multicolumn{4}{|c|}{ 2010/11 } & \multicolumn{4}{|c|}{$2011 / 12$} \\
\hline & AP & $\mathrm{AE}$ & AP & $\mathrm{AE}$ & AP & $\mathrm{AE}$ & AP & $\mathrm{AE}$ \\
\hline \multicolumn{9}{|c|}{ Dessecação } \\
\hline Com & $2,6 a$ & $1,4 \mathrm{a}$ & $2,6 a$ & $1,3 \mathrm{a}$ & $2,9 a$ & $1,4 \mathrm{a}$ & $3,0 \mathrm{a}$ & $1,6 \mathrm{a}$ \\
\hline Sem & $2,5 \mathrm{~b}$ & $1,3 b$ & $2,4 \mathrm{~b}$ & $1,2 \mathrm{~b}$ & $2,9 a$ & $1,4 \mathrm{a}$ & $3,0 \mathrm{a}$ & $1,5 b$ \\
\hline \multicolumn{9}{|c|}{ Aplicação de herbicidas } \\
\hline Única & $2,5 \mathrm{a}$ & $1,3 \mathrm{a}$ & $2,5 \mathrm{a}$ & $1,3 \mathrm{a}$ & $2,9 a$ & $1,4 \mathrm{a}$ & $3,1 \mathrm{a}$ & $1,5 \mathrm{a}$ \\
\hline Sequencial & $2,6 a$ & $1,4 a$ & $2,5 \mathrm{a}$ & $1,2 \mathrm{a}$ & $2,9 a$ & $1,4 \mathrm{a}$ & $3,1 \mathrm{a}$ & $1,5 \mathrm{a}$ \\
\hline \multicolumn{9}{|c|}{ Regulador de crescimento } \\
\hline Com & $2,5 \mathrm{a}$ & $1,3 \mathrm{a}$ & $2,4 a$ & $1,2 \mathrm{a}$ & $2,9 a$ & $1,4 \mathrm{a}$ & $3,0 \mathrm{a}$ & $1,5 \mathrm{a}$ \\
\hline Sem & $2,6 \mathrm{a}$ & $1,3 \mathrm{a}$ & $2,6 a$ & $1,3 \mathrm{a}$ & $2,9 a$ & $1,4 \mathrm{a}$ & $3,0 \mathrm{a}$ & $1,5 \mathrm{a}$ \\
\hline C.V. (\%) & 3,6 & 7,4 & 5,1 & 6,5 & 3,5 & 5,1 & 2,6 & 4,4 \\
\hline
\end{tabular}

Médias seguidas da mesma letra minúscula na coluna não diferem significativamente pelo teste de Tukey $(P<0,05)$; $C . V$.: coeficiente de variação.

Em relação à dessecação em pré-semeadura, na safra 2010/11 a ação negativa das plantas daninhas se refletiu na área foliar e no índice de área foliar (IAF) do híbrido Maximus TLTG, o que não aconteceu com o Status TL (Tabela 2). Diferenças entre híbridos quanto à área foliar também foram observadas por outros autores (SANGOI et al., 2002). Como o IAF é função de fatores como estado fitossanitário e nutricional das plantas, a matocompetição ocorrida no início do ciclo das plantas de milho do Maximus TLTG interferiu no normal desenvolvimento dessas plantas, uma vez que as invasoras e a cultura competiram tanto por espaço como por nutrientes. Já na safra 2011/12, a dessecação em pré-semeadura não afetou significativamente a área foliar e o IAF de ambos os híbridos (Tabela 2). Tal resultado pode ser atribuído ao reduzido número de invasoras que havia na época. O modo de aplicação dos herbicidas de pós-emergência também não afetou a área foliar e o IAF dos híbridos nas duas safras (Tabela 2). No ano agrícola
2010/11, com a aplicação do trinexapac-ethyl houve redução do IAF do híbrido Maximus TLTG, porém não houve diferença significativa em ambos os híbridos para a área foliar. Na safra 2011/12 a aplicação do trinexapac-ethyl ocasionou diminuição da área foliar e o IAF do híbrido Maximus TLTG (Tabela 2). Porém, a redução da área foliar constatada no presente trabalho e também relatada por Lima et al. (2010) não refletiu em alteração significativa da produtividade da cultura do milho. Dessa forma, tal consequência pode depender da proporção com que a redução da área foliar ocorre.

Na cultura do trigo, a aplicação do regulador de crescimento proporciona redução da área foliar da planta, mudando sua arquitetura, de maneira que se aumenta a eficiência fotossintética, o que pode ocasionar maior produtividade da cultura. Porém tal resultado não foi observado neste trabalho, sendo um dos fatores a se considerar na diferença da estrutura das plantas de trigo e milho. Além 
disso, como constatado neste trabalho, a cultura do milho não responde de forma significativa à aplicação do trinexapac-ethyl, como ocorre com a cultura do trigo; entretanto, mais pesquisas sobre o tema devem ser feitas para a confirmação do resultado.

Tabela 2: Área foliar por planta (AF) e índice de área foliar (IAF) dos híbridos de milho Status TL e Maximus TLTG, em função da dessecação ou não no dia da semeadura, da aplicação única ou sequencial de herbicida em pós-emergência e do uso ou não do regulador de crescimento trinexapac-ethyl, nas safras 2010/11 e 2011/12. Ponta Grossa - PR

\begin{tabular}{|c|c|c|c|c|c|c|c|c|}
\hline & \multicolumn{2}{|c|}{ Status TL } & \multicolumn{2}{|c|}{ Maximus TL TG } & \multicolumn{2}{|c|}{ Status TL } & \multicolumn{2}{|c|}{ Maximus TL TG } \\
\hline & \multicolumn{4}{|c|}{ 2010/11 } & \multicolumn{4}{|c|}{$2011 / 12$} \\
\hline Dessecação & $\mathrm{AF}\left(\mathrm{cm}^{2}\right)$ & IAF & $\mathrm{AF}\left(\mathrm{cm}^{2}\right)$ & IAF & $\mathrm{AF}\left(\mathrm{cm}^{2}\right)$ & IAF & $\mathrm{AF}\left(\mathrm{cm}^{2}\right)$ & IAF \\
\hline \multicolumn{9}{|c|}{ Dessecação } \\
\hline Com & 5669,4 a & $3,7 \mathrm{a}$ & 6123,8 a & $4,0 \mathrm{a}$ & $6065,5 \mathrm{a}$ & $4,5 \mathrm{a}$ & 6777,0 a & $5,1 \mathrm{a}$ \\
\hline Sem & $5031,5 \mathrm{a}$ & $3,4 \mathrm{a}$ & $5015,0 \mathrm{~b}$ & $3,3 \mathrm{~b}$ & $6376,4 \mathrm{a}$ & $4,8 \mathrm{a}$ & $6272,1 \mathrm{a}$ & $4,7 \mathrm{a}$ \\
\hline \multicolumn{9}{|c|}{ Aplicação de herbicidas } \\
\hline Única & $5472,8 \mathrm{a}$ & $3,5 \mathrm{a}$ & 5560,9 a & $3,6 \mathrm{a}$ & $6134,6 \mathrm{a}$ & $4,6 \mathrm{a}$ & $6637,8 \mathrm{a}$ & $4,9 a$ \\
\hline Sequencial & $5228,1 \mathrm{a}$ & $3,7 a$ & 5577,9 a & $3,8 \mathrm{a}$ & $6307,4 \mathrm{a}$ & $4,7 \mathrm{a}$ & $6411,2 \mathrm{a}$ & $4,8 \mathrm{a}$ \\
\hline \multicolumn{9}{|c|}{ Regulador de crescimento } \\
\hline Com & $5455,5 \mathrm{a}$ & $3,7 \mathrm{a}$ & $5462,0 \mathrm{a}$ & $3,3 \mathrm{~b}$ & $6041,0 \mathrm{a}$ & $4,5 \mathrm{a}$ & $6170,5 \mathrm{~b}$ & $4,6 \mathrm{~b}$ \\
\hline Sem & $5245,4 \mathrm{a}$ & $3,4 \mathrm{a}$ & 5676,7 a & $4,0 \mathrm{a}$ & $6401,0 \mathrm{a}$ & $4,8 \mathrm{a}$ & $6878,6 \mathrm{a}$ & $5,2 \mathrm{a}$ \\
\hline C.V. (\%) & 18,4 & 22,0 & 14,4 & 20,9 & 11,8 & 11,9 & 11,8 & 11,9 \\
\hline
\end{tabular}

Médias seguidas da mesma letra minúscula na coluna não diferem significativamente pelo teste de Tukey $(P<0,05)$; C.V.: coeficiente de variação.

Com relação aos componentes de rendimento, a dessecação no dia da semeadura não afetou significativamente nenhum dos componentes nos dois híbridos, em ambos os anos (Tabelas 3 e 4). Tal resultado ocorreu provavelmente porque a quantidade de plantas daninhas presente na área não foi suficiente para interferir nos componentes de rendimento. O modo de aplicação de herbicidas somente causou alteração significativa sobre a massa de mil grãos e o número de fileiras por espiga do híbrido Status TL na safra 2010/11, com valores significativamente maiores com a aplicação sequencial (Tabela 3). Os demais componentes de rendimento não obtiveram efeito significativo com o modo de aplicação de herbicida em pós-emergência, para ambos os híbridos nas duas safras (Tabelas 3 e 4). O fato de não haver resposta significativa com a aplicação sequencial não indica que essa forma de manejo não seja eficaz, uma vez que com a sua realização pode haver redução do banco de sementes de invasoras na área, assim aumentando-se a eficácia no controle das plantas daninhas, como constatado por diversos autores, a exemplo de Constantin et al. (2008), que relatam que a aplicação sequencial proporciona melhores resultados do que a aplicação única em várias culturas, inclusive na do milho. A aplicação do trinexapac-ethyl não alterou significativamente nenhum componente de rendimento avaliado em ambos os híbridos, nos dois anos agrícolas (Tabelas 3 e 4). Tal resultado pode ser atribuído à falta de resposta da cultura do milho à aplicação do regulador de crescimento ou à baixa dose aplicada.

Para o Status TL, a dessecação no dia da semeadura resultou em maior produtividade somente na safra 2010/11(Tabela 3). Já para o Maximus TLTG, a dessecação em pré-semeadura resultou em maior produtividade nos dois anos de pesquisa (Tabela 4). Na safra 2010/11, houve maior área foliar com a dessecação no dia da semeadura, o que provavelmente refletiu em maior produtividade para o híbrido Maximus TLTG, devido à maior eficiência fotossintética das plantas. Constantin et al. (2008) afirmam que mesmo considerando a total ausência de controle de plantas daninhas em pós-emergência, a simples adoção de um sistema de manejo mais efetivo no controle inicial das plantas 
daninhas proporciona ganhos na produtividade da cultura do milho, o que corrobora os resultados do presente trabalho para o híbrido Maximus TLTG nos dois anos e para o Status TL no ano 2010/11.

O modo de aplicação de herbicidas não causou efeito significativo sobre a produtividade dos híbridos, nas duas safras (Tabelas 3 e 4). Oliveira Neto et al. (2011), estudando modalidades de aplicação herbicida na cultura do milho, também não observaram diferença significativa entre a aplicação sequencial e a única na produtividade da cultura. Apesar de no presente trabalho a aplicação sequencial não ter diferido da única quanto à produtividade da cultura, na aplicação sequencial há a possibilidade de controlar fluxos mais tardios de infestação, além de reforçar o controle obtido pela primeira aplicação em espécies de difícil controle, aumentando assim a eficiência de controle, consequentemente podendo proporcionar maior produção. A ausência de diferença nesse tratamento pode ser explicada pela abundante matéria orgânica presente na superfície do solo, o que pode ter controlado de forma cultural as plantas daninhas. A aplicação do trinexapac-ethyl também não afetou significativamente a produtividade dos híbridos em ambos os anos (Tabelas 3 e 4). Segundo Lima e Lovato (1995), a não resposta da produtividade à aplicação de reguladores de crescimento pode estar relacionada à falta de acamamento da cultura, porém, outros autores (ZAGONEL; FERNANDES, 2007) observaram maior produtividade com a aplicação de regulador de crescimento mesmo não havendo acamamento das plantas de trigo.

A ausência de resultados significativos quanto ao tratamento com a aplicação do trinexapac-ethyl e a falta de interação com os demais, indicam que a cultura do milho responde de maneira pouco acentuada à aplicação do trinexapac-ethyl, porém, devido ao reduzido número de pesquisas referentes ao assunto, os resultados alcançados neste trabalho podem ser utilizados como referência para novas pesquisas sobre o tema, que são fundamentais para a confirmação dos efeitos desse regulador em milho.

Tabela 3: Número de espigas por planta (EP), massa de mil grãos (MMG), número de fileiras por espiga (FE), número de grãos por fileira (GF) e produtividade (PROD) do híbrido de milho Status TL, em função da dessecação ou não no dia da semeadura, da aplicação única ou sequencial de herbicida em pós-emergência e do uso ou não do regulador de crescimento trinexapac-ethyl, nas safras 2010/11 e 2011/12. Ponta Grossa - PR

\begin{tabular}{|c|c|c|c|c|c|c|c|c|c|c|}
\hline & \multicolumn{5}{|c|}{$2010 / 11$} & \multicolumn{5}{|c|}{$2011 / 12$} \\
\hline & EP & $\begin{array}{l}\text { MMG } \\
(\mathrm{g})\end{array}$ & FE & GF & 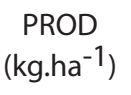 & EP & $\begin{array}{l}\text { MMG } \\
(\mathrm{g})\end{array}$ & $\mathrm{FE}$ & GF & 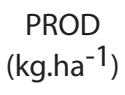 \\
\hline \multicolumn{11}{|c|}{ Dessecação } \\
\hline Com & $1,9 a$ & $366 a$ & $15 a$ & $25 \mathrm{a}$ & 9457 a & $0,9 a$ & $466 \mathrm{a}$ & $17 a$ & $26 a$ & 7854 a \\
\hline Sem & $0,8 \mathrm{a}$ & $360 a$ & $15 a$ & $25 \mathrm{a}$ & $8503 \mathrm{~b}$ & $0,8 \mathrm{a}$ & $441 \mathrm{a}$ & $17 a$ & $27 a$ & 7339 a \\
\hline \multicolumn{11}{|c|}{ Aplicação de herbicidas } \\
\hline Única & $1,7 \mathrm{a}$ & $342 \mathrm{~b}$ & $15 \mathrm{~b}$ & $25 \mathrm{a}$ & $8546 a$ & $0,7 \mathrm{a}$ & $447 a$ & $17 \mathrm{a}$ & $27 a$ & 7697 a \\
\hline Sequencial & $1,9 a$ & $386 a$ & $16 a$ & $25 a$ & $9533 a$ & $1,3 \mathrm{a}$ & $460 \mathrm{a}$ & $17 a$ & $27 \mathrm{a}$ & 7497 a \\
\hline \multicolumn{11}{|c|}{ Regulador de crescimento } \\
\hline Com & $2,2 \mathrm{a}$ & $358 a$ & $15 a$ & $25 \mathrm{a}$ & 9009 a & $0,9 a$ & $454 \mathrm{a}$ & $17 \mathrm{a}$ & $27 a$ & 7703 a \\
\hline Sem & $1,8 \mathrm{a}$ & $370 a$ & $15 a$ & $25 \mathrm{a}$ & 9071 a & $1,2 \mathrm{a}$ & $453 a$ & $17 \mathrm{a}$ & $27 a$ & 7490 a \\
\hline C.V. (\%) & 32,0 & 9,9 & 5,1 & 7,7 & 18,0 & 15,0 & 9,0 & 5,0 & 5,0 & 10,1 \\
\hline
\end{tabular}

Médias seguidas da mesma letra minúscula na coluna não diferem significativamente pelo teste de Tukey $(P<0,05)$; C.V.: coeficiente de variação. 
Tabela 4: Número de espigas por planta (EP), massa de mil grãos (MMG), número de fileiras por espiga (FE), número de grãos por fileira (GF) e produtividade (PROD) do híbrido Maximus TLTG, em função da dessecação ou não no dia da semeadura, da aplicação única ou sequencial de herbicida em pós-emergência e do uso ou não do regulador de crescimento trinexapac-ethyl, nas safras 2010/11 e 2011/12.

Ponta Grossa - PR

\begin{tabular}{|c|c|c|c|c|c|c|c|c|c|c|c|}
\hline & EP & $\begin{array}{c}\text { MMG } \\
(\mathrm{g})\end{array}$ & FE & GF & $\begin{array}{c}\text { PROD } \\
\left(\mathrm{kg}^{-1} \mathrm{a}^{-1}\right)\end{array}$ & EP & $\begin{array}{c}\text { MMG } \\
(\mathrm{g})\end{array}$ & FE & GF & $\begin{array}{c}\text { PROD } \\
\left(\mathrm{kg}^{-1} \mathrm{~h}^{-1}\right)\end{array}$ \\
\hline Cessecação \\
\hline Com & $1,8 \mathrm{a}$ & $392 \mathrm{a}$ & $17 \mathrm{a}$ & $26 \mathrm{a}$ & $9452 \mathrm{a}$ & $0,8 \mathrm{a}$ & $432 \mathrm{a}$ & $18 \mathrm{a}$ & $29 \mathrm{a}$ & $8894 \mathrm{a}$ \\
\hline Sem & $2,2 \mathrm{a}$ & $394 \mathrm{a}$ & $17 \mathrm{a}$ & $27 \mathrm{a}$ & $8516 \mathrm{~b}$ & $0,6 \mathrm{a}$ & $422 \mathrm{a}$ & $17 \mathrm{a}$ & $28 \mathrm{a}$ & $7838 \mathrm{~b}$ \\
\hline Única & $1,9 \mathrm{a}$ & $406 \mathrm{a}$ & $17 \mathrm{a}$ & $26 \mathrm{a}$ & $8873 \mathrm{a}$ & $1,3 \mathrm{a}$ & $426 \mathrm{a}$ & $18 \mathrm{a}$ & $28 \mathrm{a}$ & $8562 \mathrm{a}$ \\
\hline Sequencial & $1,7 \mathrm{a}$ & $380 \mathrm{a}$ & $17 \mathrm{a}$ & $27 \mathrm{a}$ & $9095 \mathrm{a}$ & $0,9 \mathrm{a}$ & $427 \mathrm{a}$ & $17 \mathrm{a}$ & $28 \mathrm{a}$ & $8169 \mathrm{a}$ \\
\hline
\end{tabular}

Médias seguidas da mesma letra minúscula na coluna não diferem significativamente pelo teste de Tukey $(P<0,05)$; C.V.: coeficiente de variação.

\section{Conclusão}

O tratamento em que consta a dessecação ou a falta dela em pré-semeadura foi o que promoveu mais efeitos significativos sobre as variáveis avaliadas, comprovando o prejuízo que a falta dessa prática de manejo proporciona, devido à presença de plantas daninhas na área no início de seu desenvolvimento da cultura. Em relação ao modo de aplicação dos herbicidas, tanto a aplicação única quanto a sequencial promoveram algumas alterações significativas para a cultura do milho, porém sem efeito sobre a produtividade. A aplicação do regulador de crescimento foi o tratamento que causou menos alterações nas características analisadas.

\section{RefERÊnCIAS}

ARMEL, G. R. et al. Mesotrione, acetochlor, and atrazine for weed management in corn (Zea mays). Weed Technology, v.17, n.1, p.284-290, 2003.
BURKE, I. C. et al. A comparison of weed control in herbicide-resistant, herbicide-tolerant, and conventional corn. Weed Technology, v.22, n.4, p.571-579, 2008.

CONSTANTIN, J. et al. Influência do glyphosate na dessecação de capim-braquiária e sobre o desenvolvimento inicial da cultura do milho. Planta Daninha, v.26, n.3, p.627-636, 2008.

DAVIES, P. J. The plant hormones: their nature, occourrence, and functions. In: DAVIES, P. J. Plant hormones and their role in plant growth and development. Nethrlands: Kluwer Academic, 1987. p.1-23.

HANWAY, J. J. How a corn plant develops. Ames-lowa: lowa State University, 1966. 17p. (Special Report, 48).

KOZLOWSKI, L. Período crítico de interferência das plantas daninhas na cultura do milho baseado na fenologia da cultura. Planta Daninha, v. 20, n. 3, p. 365-372, 2002.

LIMA, M. R. S; LOVATO, C. Efeito do Chlormequat sobre quatro cultivares de trigo em duas épocas de semeadura. Ciência Rural, v.25, n.3, p.371-374, 1995. 
LIMA, M. S. et al. Corn yield response to weed and fall armyworm controls. Planta Daninha, v.28, n.1, p.103111, 2010.

NORSWORTHY, J. K.; OLIVEIRA, M. J. Comparison of the critical period for weed control in wide- and narrow-row corn. Weed Science, v. 52, p. 802-807, 2004.

OLIVEIRA NETO, A. M. de et al. Modalidades de aplicação e associações de herbicidas no controle de plantas daninhas em milho em espaçamento convencional e reduzido. Semina: Ciência Agrária, v.32, n.1, p.81-92, 2011.

PHIPPS, R. H.; PARK, J. R. Environmental benefits of genetically modified crops: global and european perspectives on their ability to reduce pesticide use. Journal of Animal and Feed Sciences, v.11, n.1, p.1-18, 2002.

RADEMACHER, W. Growth Retardants: Effects on Gibberellin Biosynthesis and Other Metabolic Pathways. Annual Review of Plant Physiology and Plant Molecular Biology, v.51, p. 501-531, 2000.

RAJALA, A. Plant growth regulators to manipulate cereal growth in Northern growing conditions. 2003. 53 p. Dissertation (Academic) - Faculty of Agriculture and Forestry, University of Helsinki, Helsinki, 2003. Disponível em: <http://ethesis.helsinki.fi/julkaisut/maa/sbiol/vk/rajala/ plantgro.pdf> Acesso em: 27 nov. 2013.

SANGOI, L. et al. Acúmulo de matéria seca em híbridos de milho sob diferentes relações entre fonte e dreno. Pesquisa Agropecuária Brasileira, v.37, n.3, p.259-267, 2002.

SOUZA, C. F. L. et al. Eficiência de diferentes herbicidas na dessecação de três espécies vegetais para a cobertura do solo. Revista Brasileira de Herbicidas, v.1, n.1, p.57$60,2000$.

WEILER, E. W.; ADAMS, R. Studies on the action of the new growth retardant CGA 163'935. In: BRIGHTON CROP PROTECTION CONFERENCE-WEEDS, 1991, Switzerland. Proceedings... Switzerland: Ciba Geigy, 1991. p. 1133-1138.

ZAGONEL, J. et al. Efeito de regulador de crescimento na cultura do trigo submetido a diferentes doses de nitrogênio e densidades de plantas. Planta Daninha, v.20, n.3, p.471-476, 2002.
ZAGONEL, J.; FERNANDES, E. C. Doses e épocas de aplicação de redutor de crescimento afetando cultivares de trigo em duas doses de nitrogênio. Planta Daninha, v.25, n.2, p.331-339, 2007.

ZAGONEL, J.; MAROCHI, A. L. Épocas e modos de aplicação de glifosato na dessecação de coberturas verdes de inverno para semeadura do milho. Boletim Informativo SBCPD, v.10, p.126, 2004. 